\title{
Lamb growth rates improve as goat to sheep ratio increases
}

\author{
R.J. TOWNSEND and J.E. RADCLIFFE \\ MAF Technology, Canterbury Agriculture and Science Centre, Lincoln, Canterbury
}

\begin{abstract}
Lambs were rotationally grazed with ewes in a 'sheep only' system and with low, medium, and high proportions of wether goats from October to March on dryland perennial ryegrass-white clover pastures in Canterbury. Lambs grazed with ewes and goats until they were weaned; then they grazed ahead of other stock. Treatment ratios of adult stock on a per head basis were 3 ewes:1 goat ('low goats'), 3 ewes:2 goats ('medium goats') and 3 ewes:3 goats ('high goats'). The ewe:lamb ratio was 1:1.35 on all treatments. Lamb growth rates (g/day) were 152 for 'sheep only', and 169, 185 and 203 for low, medium and high goat treatments respectively. As each treatment lamb reached a target draft weight, it was replaced by a lighter lamb for finishing. In comparison with the 'sheep only' treatment, an extra $1.6 \mathrm{lambs} / \mathrm{ha}$ were drafted off the 'medium goat' and an -additional 2.6_lambs/ha off the 'high goat' treatment by the end of January. Increasing the proportion of goats:ewes increased the supply of white clover in pastures especially after lambs were weaned. Examination of faecal plant material showed $30 \%$ clover in the diet of lambs in a 'sheep only' system, increasing as the goat:sheep ratio increased to $60 \%$ clover in the 'high goat' treatment.
\end{abstract}

Keywords white clover, perennial ryegrass, goats, sheep,-grazing management, diet, lamb

\section{Introduction}

Few studies have been reported on mixed goat-sheep grazing on intensively grazed temperate grasslands. Enhancement of clover content in goat-grazed pastures (McGregor 1985; Lambert et al. 1987) combined with reported higher weight gains elsewhere for lambs grazing white clover (Ulyatt 1981) led to MAF Technology trials in Canterbury investigating intergrated grazing of sheep and goats. Significant benefits in lamb growth rates were recorded on irrigated pastures grazed by goats and sheep at a 1: 1 ratio compared with lamb growth rates in sheep only systems (Radcliffe \& Francis 1988; Radcliffe $\&$ Townsend, unpublished).

The present trial extended this work to examine the effects of various goat:ewe ratios on lamb production in dryland pastures. Stock effects on pastures and lamb diets were also studied.

\section{Methods}

Site

The trial was located at the MAF Templeton Research Station in Canterbury from 6 October 1989 to 12 March 1990 on pastures of perennial ryegrass (Lolium perenne) and white clover (Trifolium repens). Soils were a mosaic of Waimakariri, Templeton and Eyre fine sandy to deep silt loams (Soil Bureau 1967). Annual rainfall averages 648 $\mathrm{mm}$; rainfall during the trial period was $275 \mathrm{~mm}$ (average $245 \mathrm{~mm}$ ).

\section{Treatments}

Four treatments of 'sheep only' (ewes and lambs, mainly Coopworth) or sheep with three ratios of goats (feral X Angora wether goats) are detailed in Table-1.At the-beginning of the trial stock numbers per treatment were calculated on a metabolic liveweight basis $\left(1 \mathrm{wt}^{\mathbf{* 0 . 7 5}}\right)$ for an adult stocking rate of 11 ewes/ha. Goats replaced ewes on a metabolic liveweight basis to maintain this stocking rate. The ewe:lamb ratio on all treatments was 1:1.35.

Target liveweights were $33 \mathrm{~kg}$ for ewe lambs and 36 $\mathrm{kg}$ for cryptorchid ram lambs. At each drafting date lambs taken off the trial were replaced by lambs at lighter weights than the trial average at that date. Average weight of replacements per draft ranged from 24.5 to $28.5 \mathrm{~kg}$, 'Original' and 'replaeement' lambs-were-balanced for sex in each treatment.

\section{Management}

Stocking rate was 11 ewes/ha (see above) except from mid October till early December when it was raised to 16 ewes/ha to control spring growth. Stock treatments were grazed in a 5-paddock rotation, with each treatment having been randomly allocated its own paddocks. The rotation length was generally 28 days, reduced to 14 days for the last rotation due to scarcity of feed. Stocking rate and rotation length were chosen as a compromise between lamb performance and pasture control on the 'sheep only' treatment. All treatments were shifted at the same time. After weaning, on 27 November, adult stock 
Table 1 Stock treatment.

\begin{tabular}{lclcccc}
\hline Treatment & $\begin{array}{c}\text { Stock } \\
\text { Per head }\end{array}$ & $\begin{array}{l}\text { Metabolic' } \\
\text { Me:goat }\end{array}$ & ewe:goat & $\begin{array}{c}\text { Ha per } \\
\text { treatment }\end{array}$ & Stock numbers* per hectare \\
\hline Sheep only & $3: 0$ & $\mathbf{1}:$ o & 1.5 & ewes & goats & lambs \\
Low goat & $3: 1$ & $1: 0.25$ & 2.1 & 11.2 & -3.9 & 15.3 \\
Medium goat & $\mathbf{3 : 2}$ & $\mathbf{1}: \mathbf{0 . 5}$ & 2.6 & 7.3 & 4.6 & 12.4 \\
High goat & $\mathbf{3}: \mathbf{3}$ & $1: 0.75$ & 3.0 & 6.3 & 5.9 & a.7 \\
\hline
\end{tabular}

Metabolic ratio $\left(\mathbf{l} \mathbf{w t}^{\mathbf{* 0 . 7 5}}\right.$ ) ewe liveweight $=50 \mathrm{~kg}$, goats liveweight $36 \mathrm{~kg}$

2 Numbers at start of trial (based on 11 metabolic ewe weights per ha)

were run one paddock behind the lambs. All stock were drenched, with an anthelmintic $+\mathrm{Se}$, on to the trial and again at weaning; thereafter lambs were drenched at 4-weekly intervals. All replacement lambs were drenched on to the trial.

\section{Measurements}

Adult stock were weighed monthly while lambs were weighed every 10-14 days after weaning to monitor target liveweights. Lamb faecal samples (10 lambs per treatment) from two paddocks per rotation were collected from weaning until March. These samples were processed by the procedures of Rogerson et al. (1976), then diet components were identified using the unique cuticle patterns of the plant species.

Pasture herbage mass was measured before and after grazing in each paddock. A single-probe electronic capacitance meter was used to find paddock mean values, then 2 quadrats $\left(0.20 \mathrm{~m}^{2}\right)$ of the same mean value were cut to ground level, washed and dried to provide an estimate of paddock herbage mass. Herbage dissection samples ( 7 bulked subsamples per paddock) and grass and clover surface leaf height measurements (20 samples per paddock) were also obtained.

Numbers of ryegrass tillers and rooted white clover stolons were counted in 25 cores per paddock (each core $21.24 \mathrm{~cm}^{2}$ ) immediately after each grazing.

\section{Statistical analysis}

Lamb liveweight data were analysed by calculating individual lamb liveweight gains which were weighted in proportion to the number of days that each lamb was on the trial in each period analysed. Pasture data were grouped into pre- and post-weaning periods. All data were examined by weighted analysis of variance using the general linear models procedure of the SAS statistical package.

\section{Results}

\section{Pasture}

Above average rainfall gave high pasture masses for all but the last rotation of the trial. Green herbage mass levels (i.e. grass leaf, stem, clover and weed) before weaning were: pre graze $3280-3410 \mathrm{~kg} \mathrm{DM} / \mathrm{ha}$ and post graze $2810-3010 \mathrm{~kg} \mathrm{DM} / \mathrm{ha}$, with no significant differences between treatments $(\mathrm{P}>0.05)$. After weaning, the 'sheep only' treatment had less green herbage pre graze $(2070 \mathrm{~kg} \mathrm{DM} / \mathrm{ha})$ than did other treatments $(2310-2370 \mathrm{~kg} \mathrm{DM} / \mathrm{ha})(\mathbf{P}<0.05)$.
Post graze green herbage values showed a similar trend, with 'sheep only' (1680 kg DM/ha) being significantly less than 'high goat' $(2010 \mathrm{~kg}$ DM/ha) $(\mathrm{P}<0.05)$; other treatments had intermediate values. The clover component of pastures was the component most affected by stock treatment. Tables 4 and 5 show that as goat:sheep ratios increased from 'sheep only' to 'high goats', there was a corresponding increase (pre and post graze) in the percentage of white clover in the total herbage mass, clover DM, clover leaf height and rooted clover stolons. These effects were most apparent after lambs were weaned.

Perennial ryegrass was little affected by stock treatment. Ryegrass was a major component of pastures, comprising about $70 \%$ of the herbage mass before weaning (pre and post grazing) and about $40 \%$ of the herbage mass after weaning (pre and post grazing), with no consistent significant differences between treatments $(P>0.05)$. Before weaning, the average height of ryegrass leaves was $21 \mathrm{~cm}$ pre grazing and $13 \mathrm{~cm}$ post grazing with no significant treatment effects $(P>0.05)$. After weaning, the pregraze leaf heights for all treatments averaged $12.2 \mathrm{~cm}$ $(P>0.05)$. Post grazing, leaf height in the 'sheep only' treatment at $7.9 \mathrm{~cm}$ was significantly shorter than for all 'goat' treatments $(9.5 \mathrm{~cm})$. The number of ryegrass tillers per unit area increased as the goat:sheep ratio decreased (Table 5).

\section{Lamb diet}

Faecal samples showed a significant increase in the proportion of clover in the diet of lambs as the goat:sheep ratio increased (Table 5) from $31 \%$ in 'sheep only' to $60 \%$ in the 'high goat' treatment. Conversely, the proportion of ryegrass in lambs' diet was smallest in the 'high goat' treatment and greatest in the 'sheep only' treatment.

Table 2 Lamb liveweight gain (g/day)*

\begin{tabular}{|c|c|c|c|}
\hline Treatment & $\begin{array}{c}\text { Pre-wean } \\
\text { Oct } 89 \text {-Nov } 89\end{array}$ & $\begin{array}{l}\text { Post-wean } \\
\text { Dec 89-Mar } 90 \text { Oct }\end{array}$ & $\begin{array}{l}\text { Total } \\
\text { 89-Mar } 90\end{array}$ \\
\hline Sheep only & 225 & 111 & 152 \\
\hline Low goats & 210 & 146 & 169 \\
\hline Medium goat & 235 & 158 & 185 \\
\hline High goat & 235 & 185 & 203 \\
\hline $1 \mathrm{~s} \mathrm{~d}_{0.05}$ & 22 & 18 & 16 \\
\hline
\end{tabular}

1 Weighted liveweight gain means of original plus replacement lambs 
Table 3 Cumulative lamb draft per ha. Original plus replacement lambs.

\begin{tabular}{lccccccccc}
\hline Treatment & \multicolumn{1}{c}{ Draft date } \\
& 11 Dec & 22 Dec & 5 Jan & 18 Jan & 31 Jan & 9 Feb & 19 Feb & Mar & 12 Mar \\
\hline Sheep only & 2.6 & 2.6 & 3.9 & 3.9 & 5.3 & 8.6 & 9.2 & 14.5 & 14.5 \\
Low goat & 1.4 & 1.4 & 1.9 & 4.2 & 5.2 & 6.6 & 8.5 & 13.1 & 13.6 \\
Medium goat & 1.9 & 1.9 & 3.5 & 5.4 & 6.9 & 9.3 & 11.2 & 14.3 & 15.5 \\
High goat & 3.6 & 3.6 & 4.3 & 5.6 & 7.9 & 10.2 & 13.2 & 14.5 & 15.8 \\
\hline
\end{tabular}

\section{Stock performance}

Lambs gained significantly more weight as the proportion of goats to sheep was increased (Table 2). Overall, the highest gains were from lambs in the 'high goat' treatment ( $203 \mathrm{~g} /$ day) and the smallest gains from lambs in the 'sheep only' treatment (152 $\mathrm{g} /$ day). Benefits from the goat association were more marked after lambs were weaned (Table 2).

The number of lambs (original plus replacements) drafted off each treatment at 10-day intervals is shown in Table 3. Treatments with a higher proportion of goats enabled more lambs, both original and replacements, to be drafted at earlier dates. This advantage became most marked from mid January to mid February then declined toward the end of the trial. The average weight of lambs left on the trial at 12 March was lowest on the 'sheep only' $(29.4 \mathrm{~kg})$ and highest on the 'high goat' (32.1 $\mathrm{kg})$ treatment.

Adult stock remained in good condition throughout the trial. Ewes in the 'sheep only' treatment gained $11 \mathrm{~kg}$, significantly less than ewes in other treatments which averaged gains of $17 \mathrm{~kg}$ $(\mathrm{P}<0.05)$. Goats in all treatments gained $8-10 \mathrm{~kg}$ $(\mathrm{P}>0.05)$.

\section{Discussion}

Previous trials by MAF Technology in Canterbury established that integrated grazing of goats and sheep at a 1: 1 ratio benefited lamb growth rates (Radcliffe \& Townsend unpublished). The present trial has shown that pasture changes induced by lower ratios of goats:ewes were sufficient to maintain lamb growth benefits. Decreasing the ratio of goats:ewes in this trial resulted in a significant trend of decreasing clover content in pastures, thereby providing less clover DM on offer to lambs (Table 4). Analysis of faecal samples showed a similar trend, with the percentage of clover in lamb diets decreasing as the proportion of goats in a treatment decreased (Table 5).

Although herbage mass on offer to lambs may have been slightly higher in the higher goat:ewe ratio treatments, due probably to the lower numbers of lambs/ha or possibly to ascribing to low an equivalence to the goats, this is unlikely to be the major factor involved in the improved lamb liveweight gains. Residual green herbage mass levels, which are a better indicator of lamb weight gain than total herbage mass (Butler et al. 1987), were generally above the total herbage mass levels recommended for lamb weight gains of 180-200 g/day (Milligan 1981), indicating that total available herbage mass would not limit weight gains on this trial. These results point to lower pasture clover contents as being a major factor responsible for lower lamb liveweight gains observed as the goat:ewe ratio decreased.

The potential for extra clover growth in mixed goat-sheep pastures is seen in the numbers of rooted clover stolons-(-Table 4).-An-extra-1-4-to-4-2-million rooted clover stolons/ha, with attendant leaf bud sites, were possible from the goat:sheep ratios used here compared with 'sheep only' grazing systems. Perhaps clover growth was stimulated by the microclimates in pastures grazed by goats which were visually denser and had taller clover canopies.

Table 4 White clover $\mathrm{kg}$ DM/ha, percentage of white clover in total herbage mass $(\% \mathrm{HM})$ and surface height of clover leaves.

\begin{tabular}{|c|c|c|c|c|c|c|c|c|c|}
\hline \multirow[t]{3}{*}{ Treatment } & \multicolumn{9}{|c|}{ Trial period } \\
\hline & & Pre-wean & & & ost-wean & & & Overall & \\
\hline & $\begin{array}{c}\mathbf{k g} \\
\mathrm{DM} / \mathrm{ha}\end{array}$ & $\% \mathrm{H} \mathrm{M}$ & $\begin{array}{c}\text { Height } \\
\mathrm{cm}\end{array}$ & $\begin{array}{c}\mathrm{kg} \\
\mathrm{DM} / \mathrm{ha}\end{array}$ & $\% \mathrm{H} \mathrm{M}$ & $\begin{array}{c}\text { Height } \\
\mathrm{cm}\end{array}$ & $\begin{array}{c}\text { kg } \\
\text { DM/ha }\end{array}$ & $\% \mathrm{H} \mathrm{M}$ & $\begin{array}{c}\text { Height } \\
\mathrm{cm}\end{array}$ \\
\hline \multicolumn{10}{|l|}{ Pre-graze } \\
\hline Sheep only & 460 & 13 & 12.9 & 260 & 7 & 5.5 & 330 & 9 & 8.0 \\
\hline Low goats & 440 & 12 & 14.2 & 370 & 10 & 6.6 & 390 & 10 & 9.2 \\
\hline Medium goats & 500 & 15 & 13.5 & 460 & 11 & 6.8 & 470 & 12 & 9.1 \\
\hline High goats & 530 & 16 & 13.3 & 570 & 15 & 7.3 & 560 & 15 & 9.4 \\
\hline $\mathrm{lsd}_{0.05}$ & 160 & 4 & 1.8 & 100 & 2 & 0.8 & 90 & 2 & 0.9 \\
\hline \multicolumn{10}{|l|}{ Post-graze } \\
\hline Sheep only & 150 & 5 & 5.1 & 150 & 4 & 3.0 & 150 & 4 & 3.1 \\
\hline Low goats & 230 & 7 & 5.6 & 220 & 6 & 4.0 & 230 & 7 & 4.5 \\
\hline Medium goats & 240 & 8 & 6.1 & 290 & 8 & 4.4 & 270 & 8 & 4.9 \\
\hline High goats & 280 & 9 & 6.6 & 400 & 11 & 4.8 & 360 & 10 & 5.4 \\
\hline $\operatorname{lsd}_{0.05}$ & 90 & 2 & 0.9 & 80 & 2 & 0.5 & 70 & 2 & 0.4 \\
\hline
\end{tabular}


Table 5 Rooted white clover stolons, perennial ryegrass tillers and percentage of white clover in lamb diets over trial period.

\begin{tabular}{|c|c|c|c|}
\hline Treatment & Clover stolons per sample' & Ryegrass tiller per sample' & \% clover in diet' \\
\hline Sheep only & 1.8 & 14.2 & 30.6 \\
\hline Low goats & 2.1 & 13.0 & 34.0 \\
\hline Medium goats & 2.3 & 12.4 & 46.1 \\
\hline High goats & 2.1 & 12.8 & 59.7 \\
\hline $\mathrm{lsd}_{0.05}$ & 0.3 & 1.6 & 11.7 \\
\hline
\end{tabular}

1 Sample area $=21.24 \mathrm{~cm}$ ' $\left(1 \mathrm{ha}=21.24 \mathrm{~cm}^{2} \times 4.7\right.$ million $)$

2 Measured from weaning until the end of the trial.

Improving the clover content of pastures increases the nutritive value of pastures for stock and stimulates grass growth through added supplies of fixed and recycled nitrogen.

Substituting goats for ewes and so reducing numbers of lambs/ha in mixed goat-sheep grazing situations clearly affects economic returns per hectare. In the present trial, replacing drafted lambs with 'finishing' lambs from off the trial gave similar or greater total production of drafted lambs/ha from the integrated goat-ewe treatments compared to the 'sheep only' treatment. However, in dryland farming, finishing lambs early is of prime importance. This trial has shown that replacing some ewes with goats can finish more lambs/ha earlier in the season than can an all sheep system. Returns per hectare would depend on such factors as whether those 'finishing' lambs came from elsewhere on the property or were bought in, and also on schedule prices at each draft.

\section{Conclusions}

1. Lambs gained weight faster on pastures conditioned by goat grazing, with greater gains as the goat:ewe ratio was increased.

2. The major effect of goat grazing was to increase the clover component in pastures, even at 1 goat:3 ewes (3 goats/ha).

3. Clover increased proportionally to goat grazing pressure and more clover was eaten by lambs as the goat:ewe ratio increased.

4. If clover growth were checked for any reason, such as drought, then the direct benefit of goat grazing on lamb growth rates would probably be lost.

\section{Acknowledgements}

Staff at Templeton Research Station and Rick Davison for assistance with stock work. David Baird for assistance with the statistical analyses and Joy Talbot for plant cuticle identifications.

\section{REFERENCES}

Butler, B.M.; Hoogendoorn, C.J.; Richardson, M.A. 1987. Pasture quality and animal performance over late spring and summer. Proceedings of the NZ Society of Animal Protection 47: 31-33.

Lambert, M.G.; Clark, D.A.; Betteridge, K. 1987. Grazing behaviour of goats on weed infested hill pastures in New Zealand. Proceedings of the 4th International Conference on Goats 2: 1307.

McGregor, B.A. 1985. Complementary grazing of goats and sheep in the temperate zone. Proceedings of the 1 st International Cashmere Seminar. Australian National University, Canberra. pp. 105-123.

Milligan, K.E. 1981. Putting grazing management into practice: the residual dry matter technique. In NZ Farmer guide to grazing management. Supplement to the New Zealand Farmer, December 10, 1981.

Radcliffe, J.E.; Francis, S.M. 1988. Goat farming practices on high producing pastures. Proceedings of the $\mathbf{N Z}$ Grassland Association 49: 29-32.

Rogerson, S.J.; Stevens E.J.; Hughes J.G. 1976. An improved preparation technique for identification of plant cuticle in animal faeces. NZ Journal of Botany 14: $117-119$.

Soil Bureau 1967. Soils of the Downs and Plains. Canterbury and North Otago. NZ Soil Bureau bulletin 14: $1-92$.

Ulyatt, M.J. 1981. The feeding value of temperate pastures. In Morley, F.H.W. (Ed.) Grazing Animals. World Animal Science 1B. Elsevier. 